\title{
Percutaneous Nephrolithotomy in Supine Position: A Single Center Experience
}

\section{Supin Pozisyonda Perkütan Nefrolitotomi: Tek merkez deneyimi}

\author{
Erdem Öztürk ${ }^{1}$, Taha Numan Yıkılmaz ${ }^{1}$ \\ ${ }^{1}$ Ankara Dr. Abdurrahman Yurtaslan Onkoloji Eğitim ve Araştırma Hastanesi, Ankara
}

\section{ÖZET}

GÍRİ̧̧ ve AMAÇ: Perkütan nefrolitotomi (PNL), böbrek taşlarının tedavisinde sık kullanılan bir tedavi yöntemidir. PNL genellikle pron pozisyonda yapılamasına rağmen pozisyonel bazı dezavantajlar göz önüne alınarak supin pozisyonda PNL geliştirilmiştir. Bu çalışmada kliniğimizde supin posizyonda yapılan PNL sonuçlarımızın sunulması amaçlanmıştır.

YÖNTEM ve GEREÇLER: Kliniğimizde Kasım 2016-Haziran 2018 tarihleri arasında böbrek taşı nedeniyle supin pozisyonda PNL yapılan 74 hastanın verileri retrospektif olarak tarandı. Hastaların yaş, cinsiyet, ortalama taş boyutu, operasyon süresi, floroskopi süresi, hospitalizasyon süresi, taşsızlık oranları ve cerrahi sonrası komplikayonlar kaydedildi.

BULGULAR: Çalışmaya dahil edilen 74 hastanın 46'sı erkek, 28'i kadındı. Hastaların ortalama yaşı $52 \pm 14.6$ olarak hesaplandı. Ortalama taş boyutu $2.4 \pm 0.62 \mathrm{~cm}$ idi. Ortalama operasyon süresi $58.7 \pm 19.24 \mathrm{dk}$, floroskopi süresi 3.61 $\pm 1.35 \mathrm{dk}$, ortalama hospitalizasyon süresi ise 2.9 (1-6) gün olarak saptandı. Hasta serimizdeki taşsızlık oran $1 \% 86.48$ olarak hesapland1. Takiplerde komplikasyon izlenme oranı ise $\% 6.7$ olarak bulundu.

TARTIŞMA ve SONUÇ: Böbrek taşı tedavisinde supin PNL yüksek taşsızlık oranları ile etkin ve güvenilir bir tedavi seçeneğidir. Hasta ve cerrah konforu, işlem sırasında üretral girişim yapılabilmesi ve kabul edilebilir anestezik riskleri ile PNL cerrahilerinde supin posizyon tercih edilebilecek bir yaklaşımdır.

Anahtar Kelimeler: Supin pozisyon, Perkütan nefrolitotomi, taşsızlık oranı

\begin{abstract}
INTRODUCTION: Percutaneous nephrolithotomy (PNL) is a widely used treatment choice for renal stones. Usually, PNL has been performed in prone position but due to some disadvantages of this pozisiton supine PNL has been described. In this study, we aimed to present the outcomes of PNL applied in supine position in our clinic.

MATERIAL and METHODS: Retrospective data was collected on 74 patients underwent PNL in supine position between November 2016 and June 2018. Patients' demographics, stone size, operation time, fluoroscopy time, hospitalization time, stone free rates and complications were collected.

RESULTS: Fourty-six men, twenty-eight women underwent supine PNL with a mean stone size of $2.4 \pm 0.62 \mathrm{~cm}$. The mean age of the patients were $52 \pm 14.6$ years. The mean operation, fluoroscopy and hispitalization time were $58.7 \pm 19.24 \mathrm{~min}, 3.61 \pm 1.35 \mathrm{~min}$ and 2.9 (1-6) days, respectively. The stone free rates among 74 patients was $86.48 \%$. During the follow-up period, the total complication rate was $6.7 \%$.

DISCUSSION and CONCLUSION: For treatment of kidney stone supine PNL is a safe and effective procedure with high stone free rates. Supine position can be preferred in terms of patient and surgeon comfort, allowing urethral Access during the surgery and acceptable anesthetic risks.
\end{abstract}

Keywords: Supine Position, Percutaneous nephrolithotomy, stone free rate 


\section{GIRIS}

Perkütan nefrolitotomi (PNL) operasyonu hem Avrupa Üroloji Birliği (EAU) hem de Amerika Üroloji Derneği (AUA) derneği kılavuzlarında $2 \mathrm{~cm}$ üstündeki böbrek taşlarının ve $2 \mathrm{~cm}$ altında ESWL dirençli böbrek taşlarının tedavisinde birinci basamak tedavi yöntemi olarak önerilmektedir (1,2). 1955 y1lında Goodwin ve arkadaşları (3) bir hastada pron posizyonda renal kasesi tanımlamışlar, ve sonrasında ilk PNL operasyonu 1976 yilında Fernström ve arkadaşları (4) tarafindan başarıyla uygulanmıştır. Zaman içerisinde minyatürize olan aletler ve taş kırma ekipmanlarındaki teknolojik gelişimlerle birlikte günümüzde PNL yüksek başarı oranları ve düşük komplikasyon oranları ile dünya genelinde sıklıkla yapılan güvenli bir cerrahi girişim olmuştur.

Her ne kadar pron pozisyonda yapilan PNL'nin başarı oranları yüksek olsa da hastaların supin pozisyonda üreteral katater takılımını takiben pron pozisyona geçişin anestezi altında yapılmasına bağlı olası riskler, hemodinamik değişiklikler, olası kardiyak sorunlarda müdahalenin gecikmesi gibi zorluklar cerrahları farklı pozisyonaların araştırılmasına yönlendirmiştir. İlk kez 1987 yılında Valdivia ve arkadaşları (5) supin pozisyonda PNL operasyonunu tanımlamışlardır. Kardiyovasküler stabilitenin daha iyi korunması, pozisyon değişimi olmaması nedeniyle cerrahi sürenin kısalması ve modifiye olan pozisyonel tekniklerle eş zamanlı üretral akses yapilabilmesi gibi avantajları sayesinde birçok cerrah tarafindan kullanımı yaygınlaşmıştır.

Biz bu çalışmamızda kliniğimizde yapılan supin PNL sonuçlarımızı sunmayı amaçladık.

\section{GEREÇ ve YÖNTEM}

Kliniğimizde Kasım 2016-Haziran 2018 tarihleri arasında böbrek taşı nedeniyle supin pozisyonda PNL yapılan 74 hastanın verileri retrospektif olarak tarand1. Bütün hastalara cerrahi öncesi rutin laboratuar testleri yapıldi. Preoperatif dönemde hastalar taş lokalizayonu ve boyutu açısından düşük doz kontrastsız bilgisayarlı tomografi (BT) ile değerlendirildi. Hastaların yaş, cinsiyet ortalama taş boyutu, operasyon süresi, floroskopi süresi, hospitalizasyon süresi, taşsızlık oranları ve cerrahi sonrası komplikayonlar kaydedildi.

\section{Cerrahi teknik}

Preoperatif profilaksi amaciyla 1x2 gr seftriakson intravenöz olarak uygulanan, posterior aksiller çizgisi, iliak kresti ve 12 . kotu kalem yardımıyla belirlenen hastalara genel anestezi verildi. Hastalar Galdakao Modifiye Supin Valdivia pozisyonu verildi (6). Bu pozisyonda tanımlandığı gibi hastnın taşla ipsilateral alt ekstremitesi ekstansiyona, kontralateral ekstremitesi abdüksiyon ve fleksiyona alındı. Cerrahini yapılacağı bölge lomber bölge silikon yastıklar yardımıyla yaklaşık olarak 20 derece yukarı kaldırıldı. İpsilateral üst ekstremite göğüs kafesini çaprazlayarak karşı tarafa doğru uzatıldı ve tespit edildi. Pozisyon verilmesini takiben sistoskopi ile taşın bulunduğu tarafa açık uçlu üreter katateri takıldı. Retrograd pyelografi çekilerek giriş yapılacak tract belirlendi ve posterior aksiller çizginin önüne geçilmeksizin renal akses sağlandı. Amplatz dilatatörler (Microvasive/Boston Scientific, Natick, MA) yardımı ile dilatasyon yapıldı ve 26 fr nefroskop (Karl Storz) ile toplayıcı sisteme girildi. Taşlar pnömotik ve/veya ultrasonic litotriptörle kırılarak dışarıya alındı. Cerrahiyi sonlandirmadan önce toplayıc1 system ve ureteral pasaj antegrad pyelografi ile control edildi. Hastalara 14 fr perkütanöz mallekot nefrostomi yerleştirilerek işleme son verildi. Operasyon süresi perkütan iğnenin girişi ile nefrostomi tüpünün yerleştirilmesi arasındaki süre olarak alındı.

Postoperative 1. günde hastalara direct üriner system grafisi çekildi ve rezidüel taş açısından değerlendirildi. Hastaların hemogram, üre ve kreatinin değerleri takip edildi. Nefrostomi katateri çekilmeden önce antegrad piyelografi çekildi. Ekstravasyonu olmayan ve mesaneye opağın geçişinin görüldüğü hastalarda nefrostomi katateri çekildi. Giriş traktından idrar kaçağı kesilen hastalar taburcu edildi. Cerrahi sonras1 1. ayda kontrole çağırılan hastalar taşsızlık açısından BT veya ultrasonografi ile tekrar değelendirildi. Taşsızlığın sağlandığı veya $4 \mathrm{~mm}$ altında rezidüel fragman izlenen hastalarda prosedür başarılı olarak değerlendirildi. 


\section{BULGULAR}

Çalışmaya dahil edilen 74 hastanın 46'sı (\%62,1) erkek, 28i (\%37.9) kadındı. Hastaların ortalama yașı $52 \pm 14.6$ olarak hesaplandı. Ortalama taş boyutu $2.4 \pm 0.62 \mathrm{~cm}$ olarak saptandı. Tüm hastalara tek akses yapıldı. Tüm girişler floroskopi altında yapıldı. Peruktan iğne girişi ile nefrostomi kataterinin takılması arasındaki süre operasyon zamanı olarak alındığında ortalama süre $58.7 \pm 19.24 \mathrm{dk}$ olarak bulundu (Tablo 1). Cerrahi boyunca ortalama floroskopi süresi $3.61 \pm 1.35 \mathrm{dk}$ idi. İşlem bitimini takiben antegrad piyelografi çekilen hastalara perkütan mallecot nefrostomi takılarak işlem sonlandırıldı.

Tablo 1. Supin PNL vakalarının verileri

\begin{tabular}{|l|c|}
\hline & $\begin{array}{c}\text { Supin PNL } \\
(\mathrm{n}=74)\end{array}$ \\
\hline Cinsiyet & $28(\% 37.9)$ \\
-Kadın & $46(\% 62.1)$ \\
-Erkek & $52 \pm 14.6$ \\
\hline Yaş (yıl) & $2.4 \pm 0.62$ \\
\hline Taş boyutu (cm) & $58.7 \pm 19.24$ \\
\hline Cerrahi süre (dk) & $3.61 \pm 1.35$ \\
\hline Floroskopi süresi (dk) & $2.9(1-6)$ \\
\hline Hospitalizasyon süresi (gün) & $\% 86.48$ \\
\hline Taşsızlı oranı & $\% 6.7$ \\
\hline Komplikasyon & $\% 0$ \\
\hline -Transfüzyon & \\
-Komşu organ yaralanması & \\
\hline
\end{tabular}

Ortalama hospitalizasyon süresi 2.9 (1-6) gündü. Nefrostomi katateri 18 (\%24.3) hastada postoperatif ilk gün alınırken $52(\% 70.2)$ hastada postoperatif 2. gün, $4(\% 5.4)$ hastada ise postoperatif 3. gün alındı. Hiçbir hastada kolon veya komşu organ yaralanması görülmedi. 5 (\%6.7) hastada postoperatif kan transfüzyonu gerektiren hemogram düşüklüğü izlendi. Operasyon sonrası çekilen direkt üriner sistem grafisi görüntülerine göre 64 hastada taşsızlık sağlandığı görüldü ve taşsızlık oranı $\% 86.48$ olarak hesaplandi.

\section{TARTIŞMA}

Üriner sistem taş insidansı coğrafik, iklimsel, etnik, diyet eve genetik faktörlere göre değişiklik göstermekle birlikte, batı toplumlarında hayat boyu ürolithiasis görülme sıklığı erkeklerde \%12, kadınlarda ise \%6'dır (7). Günümüzde büyük taşların tedavisinde peruktan nefrolitotomi halen standart prosedür olarak kılavuzlar tarafından önerilmektedir. 1976 yılında ilk defa pron pozisyonda yapılan bu cerrahi uzun süreler pron pozisyonda yapılmış bunun taşa en güvenli ulaşım olduğu düşünülmüştür (4). 1987 y1lında suppin pozisyonun tanımlanmasina, pron pozisyon bilinen zorluklarına ve risklerine rağmen dünya genelinde birçok ürolog tarafından etkin ve güvenli olarak uygulanmaktadır. Bugün için ülkemizde ve dünyada birçok merkezde PNL işlemi prone pozisyonda yapılmaktadır. Prone pozisyonun daha fazla tercih edilmesinin sebebi ürologların supine pozisyona alışkın olmamaları ve buna bağlı olarak tecrübelerinin az oluşudur. 2010 yılında İngiliz Ürologlar Birliği (BAUS) tarafından yapılan bir çalışmada cerrahların sadece \%6's1 supin pozisyonu tercih ettiği belirtilmiştir (8). Enüroloji Derneği tarafından 2011yayımlanan bir çalışmada ise dünya genelinde supin pozisyon tercihinin \%20'lerde olduğu vurgulanmıştır (9). Bu veriler supin pozisyonun giderek yaygınlaştığını göstermektedir.

Valdivia ve ark. (5) 1987 yılında supin poziyonda renal aksesi tanımladıktan sonra 1998 y1linda 557 hastalik serilerini yayınlamışlardır (10). Sonrasında birçok çalışmada supin ve pron repkütan gerek başarı gerekse avantaj ve dezavantajları açısından karşılaştırılmıştır.

$\mathrm{Wu}$ ve arkadaşları (11) tarafindan yayınlanan bir metaanalize 1469 supin pozisyon cerrahisi ile 4837 pron pozisyon cerrahisi sonuçları karşılaştırılmıştır. Supin pozisyonda taşsızlık oranı \%82,4 iken pron pozisyonda $\% 82.1$ olarak belirtilmiş ve istatistiksel olarak herhangi bir fark olmadığı vurgulanmıştır. Komplikasyon oranları da benzer olarak raporlanan iki pozisyon arasındaki en önemli farkın cerrahi süre olduğu bulunmuştur. Supin pozisyonda cerrahi süre $65 \pm 15 \mathrm{dk}$ iken pron pozisyonda $90 \pm 15 \mathrm{dk}$ olarak bulunmuştur. Liu ve arkadaşları (12) tarafindan 2010 yılında yayınlanan başka bir metaanalizde ise iki pozisyon arasında taşsızlık oranı, transfüzyon gereksinimi, komplikasyon izlenme, ateş açısından herhangi bir fark saptanmazken supin pozisyonda cerrahi sürenin daha kısa olduğu vurgulanmıştır. Her iki metaanaliz sonucunda da pron ile supin pozisyon arasında taşsızlık ve komplikasyon oranları açısından herhangi bir üstünlük olmadığı fakat supin pozisyonda cerrahi sürenin daha kısa olduğu sonucuna 
varılmıştır. $\mathrm{Bu}$ bilgilerinin aksini iddia eden çalışmalarda mevcuttur. Astroza ve arkadaşları (13) tarafından yapılan bir çalışmada pron pozisyonda yapılan 1079 hastanın verileri supin pozisyonda yapılan 232 hastanın verileri ile karşılaştırılmıştır. Hem cerrahi süre hem de taşsızlık oranı pron pozisyonda daha yüksek olarak saptanmıştır. Bu verilerin cerrahların pron pozisyondaki deneyimlerine bağlı olduğu düşünülmüştür. Ülkemizden bu konuda yapılan ve tek cerrahın deneyimlerinin yayınladığ 1 bir çalışmada 39 supin PNL hastası ile 48 pron PNL hastası karşılaştırılmış ev taşsızlık oranları açısından iki grup anlamlı fark bulunmamıştır. Her ne kadar literatürde aksini iddia eden çalışmalar olsa da geniş serilerin dahil edildiği metaanalizlerde de saptandığı üzere genel görüş, iki pozisyon arasında taşsızlık oranları ve komplikasyon görülme sıklığı açısından fark olmadığı yönündedir. Biz de kliniğimizde bu çalışmalar 1şığında 2016 yılından beri supin PNL'yi tercih etmekteyiz.

Bizim serimizde elde ettiğimiz taşsızlık oranımız \%86.48 olup literatürdeki verilerle uyumludur. Cerrahi süremiz $58.7 \pm 19.24 \mathrm{dk}$ olarak hesaplanmış olup bu verinin de literatürle uyumlu olduğu görülmüştür. Artan cerrahi tecrübelerimizle başarı oranlarımız yükseleceği, cerrahi süremizin ise düşeceği görüşündeyiz.

Kullanımı giderek yaygınlaşan supin PNL'nin güvenilirliği de bir çok çalıma tarafindan incelenmiştir. Wu ve arkadaşlarının (11) metaanalizinde transfüzyon ornları supin PNL için \%8.8, pron PNL için \%4.3 olarak saptansa da aradaki fark istatistiksel olarak anlamlı değildir. Bizim çalışmamızdaki 5 $(\% 6.7)$ hastada tranfüzyon gereksimi olmuştur ki oranımız literatür ile uyumludur.

Kolon yaralanması PNL'nin en önemli komplikasyonlarından biridir. Preoperatif dönemde supin pozisyonda çekilen BT ile cerrahiye alınan hastalar pron pozisyona çevrildiğinde kolon retrorenal alana transpozisyone olabilmektedir. $\mathrm{Bu}$ konuda Hopper ve arkadaşları (14) tarafindan yapılan çalışmada 97 hastaya kolonun yer değişimini saptamak üzere hem supin hem pron posizyonda BT çekilmiştir. Supin pozisyonda $\% 1.9$ oranın da saptanan retrorenal kolon, pron çekilen BT'de \%10'a çıkmıştır. Bu çalışma 1şı ğında pron PNL planlanan hastalara operasyon öncesi değerlendirme sirasında çekilen BT'nin pron pozisyonda çekilmesi önerilse de bu bilginin günümüzde kullanımı kısıtlıdır. Literatürde işlem sırası kolon yaralanma oranı $\% 0.5$ olarak verilmesine rağmen (15) bizim serimizde hiçbir hastada kolon veya komşu organ yaralanması görülmemiştir.

Pron pozisyonda öncelikle litotomideki hastaya üreteral kataterin takılmasını takiben hasta pron pozisyona alınmaktadır. Pron pozisyona alınan hastada sonrasında üretral herhangi bir giriş yapmak mümkün değildir. Supin pozisyonda ise Galdakao Modifiye Supin Valdivia pozisyonu sayesinde hastalara eş zamanlı üretral girişimler yapılabilmektedir $(16,17)$. Özellikle farklı kalikslerde taşları olan ve PNL ile ulaşılamayan taşlarda flexible üreterorenoskop yardımıyla kalan taşların kırılması hasta açısından önemli bir avantajdır. Sağlanan aksesin prone pozisyondakine kıyasla daha yatay ve aşağıya eğimli olması da toplayıcı sistemde düşük basınç oluşmasına ve bu sayede taş kırılması sonrası oluşan küçük fragmanların kendiliğinden dışarı çıkmasına yardımcı olmaktadır (18). Bu iki avantaj sayesinde rezidü taş saptanma oranı azalmakta taşsızlık oranı ise artmaktadır.

Operasyon sürelerinde kısalma ve buna bağlı daha az miktarda anestezik madde kullanılmas1 supin pozisyonda olas1 kardiyovasküler riskleri azaltmaktadır. Hasta repozisyonuna gerek kalmaması nedeniyle pron pozisyona geçerken görülebilecek olası yaralanmalarında önüne geçilmektedir. Supin pozisyonun sadece hasta için değil cerrah açısından avantajları mevcuttur. Renal aksesin tamamlanmasını takiben cerrahın operasyona oturur pozisyonda devam edebilmesi cerrahın konforu açısından önemlidir (17). Bizim klinik pratiğimizde de birçok hastada akses sağlanmasını takiben cerrahiye oturur pozisyonda devam edilmektedir.

\section{SONUÇ}

Supin pozisyonda PNL; eş zamanlı üreterorenoskopik girişime imkan sağlayan, ameliyat süresini önemli ölçüde kısaltan, anestezik açıdan kardiyovasküler ve ventilatuar avantajlar sağlayan bir yöntemdir. Pron pozisyona kiyasla benzer etkinlik ve güvenilirlik ile daha yaygın kullanılmasını önermekteyiz.

\section{Çıkar Çatışması: Yok}




\section{REFERANSLAR}

1. Preminger GM, Tiselius HG, Assimos DG, et al. 2007 guideline for the management of ureteral calculi. $\mathrm{J}$ Urol 2007;178:2418- 34.

2. Tiselius HG, Ackermann D, Alken P, Buck C, Conort P, Galluci M. Guidelines on urolithiasis. Eur Urol 2001;40:362-71.

3. Goodwin WE, Casey WC, Woolf W. Percutaneous trocar (needle) nephrostomy in hydronephrosis. J Am Med Assoc 1955;157:891-4.

4. Fernstrom I, Johansson B. Percutaneous pyelolithotomy. A new extraction technique. Scand J Urol Nephrol 1976;10: 257-9.

5. Valdivia Uria JG, Lanchares SE, Villaroya RS, Taberner LJ, Abril BG, Aranda Lassa JM, et al. Percutaneous nephrolithectomy: simplified technic (preliminary report). Arch Esp Urol 1987;40:177-80.

6. Hoznek A, Rode J, Ouzaid I, et al. Modified supine percutaneous nephrolithotomy for large kidney and ureteral stones: technique and results. Eur Urol 2012;61:164-70.

7. Stamatelou KK, Francis ME, Jones CA, et al. Time trends in reported prevalence of kidney stones in the United States: 1976-1994. Kidney Int. 2003;63:18171823.

8. Armitage J, Irving S, Burgess N. Percutaneous Nephrolithotomy in the United Kingdom: Results of a Prospective Data Registry. Eur Urol. 2012; 61(6): p. 1188-93.

9. De la Rosette J, Assimos D, Desai M, et a 1. The Clinical Research Office of the Endourological Society percutaneous nephrolithotomy global study. J Endouro. 2011; 25(1): p. 11-17.

10. Valdivia Uría JG, Valle Gerhold J, López López JA, et al. Technique and complications of percutaneous nephroscopy: experience with 557 patients in the supine position. J Urol 1998;160:1975-8.

11. Wu $\mathrm{P}$, Wang $\mathrm{L}$, Wang $\mathrm{K}$. Supine versus prone position in percutaneous nephrolithotomy for kidney calculi: a meta-analysis. Int Urol Nephrol. 2011; 43: p. 67-77.

12. Liu I, Sheng S, Xu Y, Wei Q. Systematic review and meta-analysis of percutaneous nephrolithotomy for patients in the supine versus prone position. J Endourol. 2010; 24: p. 1941-6.

13. Astroza G, Lipkin M, Neisius A, et al. Effect of supine vs prone position on outcomes of percutaneous nephrolithotomy in staghorn calculi: results from the Clinical Research Ofice of the Endourology Society Study. Urology. 2013; 82: 1240-1244.

14. Hopper K, Sherman J, Luethke J, Ghaed N. The retrorenal colon in the supine and prone patient. Radiology. 1987 Feb; 162(2): p. 443-446.

15. Amón Sesmero JH, Del Valle González N, Conde Redondo C, et al. Comparison between Valdivia position and prone position in percutaneous nephrolithotomy. Actas Urol Esp 2008;32:424-9.

16. De la Rosette JJ, Tsakiris $P$, Ferrandino MN, Elsakka AM, Rioja J, Preminger GM. Beyond prone position in percutaneous nephrolithotomy: a comprehensive review. Eur Urol 2008;54:1262-9.

17. Basiri A, Mohammadi Sichani M. Supine percutaneous nephrolithotomy, is it really effective? A systematic review of literature. Urol J 2009;6:73-7.

18. Ng MT, Sun WH, Cheng CW, Chan ES. Supine position is safe and effective for percutaneous nephrolithotomy. J Endourol 2004;18:469-74. 